\title{
Equilibrio Químico: Una propuesta investigativa para la formación inicial de profesores de química
}

\author{
Chemical Equilibrium: A investigative proposal for the initial formation of chemistry \\ professors
}

Carmen Andrea Aristizábal Fúquene ${ }^{1}$, Royman Pérez Miranda² y Rómulo Gallego Badillo²

${ }^{1}$ Profesora Instituto superior de Educación Téanica, INSUTEC, Bogotá, Colombia. ${ }^{2}$ Profesores Investigador Universidad Pedagógica Nacional de Bogotá, Colombia. Grupo de Investigación Representaciones y Conceptos Cientúficos-Grupo IREC. andrea aristizabal@hotmail.com royman@pedagogica.edu.co rgallego@pedagogica.edu.co

\section{Resumen}

Se presenta aquí una propuesta i sobre los principios fundamentales para una práctica docente sobre equilibrio químico desde un análisis del desarrollo histórico-epistemológico con el que se fundamenta la mirada pedagógica y didáctica para hacerlo objeto de trabajo en el aula. El planteamiento se enfoca en los aspectos centrales de la formación profesional de la formación inicial de profesores de ciencias.

\section{Abstract}

This work presents the fundamental principles for the teaching of chemical equilibrium from a historic-epistemological analysis. This analysis constitutes the pedagogical and didactic foundations of the activities done in dass. The proposal focuses on the central issues related to initial professional training of teachers

Key words

Didactics of sciences; chemical equilibrium; mission of the knowledge.

\section{Equilibrio Químico: Un modelo abstracto en construcción}

Los resultados de las investigaciones didácticas que se han realizado acerca del equilibrio químico, muestran la poca comprensión en los que han abordado, por alguna razón, su estudio. Esta dificultad estriba en que los estudiantes no han construido ideas previas sobre dicha temática, no hacen relaciones significativas con la realidad y al uso de la terminología que se requiere para su descripción, explicación y predicción. Además, tal dificultad se debe también a la demanda de un pensamiento abstracto que permita la ubicación de los procesos de nivel atómico-molecular razón por la cual es escasa la posibilidad de transformación de los conceptos y su utilización en otras disciplinas, (Raviolo, Baumgartner, Lastres y Torres, 2001). Además, muestran que equilibrio químico exige una elevada jerarquía conceptual, es decir, que se necesita para su comprensión temas previos como: reacción química, gases, estequiometría, nociones de cinética y termoquímica. Esta carencia ha obligado que tal contenido curricular se aprenda por repetición y en consecuencia la no reflexión y discusión que para tal efecto exige. (Raviolo, 2001).

Por otro lado, se analizan auál es la mejor forma para que los estudiantes comprendan significativamente los fenómenos que suceden en el equilibrio químico para lo cual sugieren los investigadores el uso de analogías (Raviolo y Garritz, 2007) o de imágenes (Raviolo, 2006). 
Postulan que esa comprensión es posibilitada por el razonamiento analógico. Las analogías y el uso de imágenes permiten : enseñar algo desconocido a partir de algo conocido; el pensamiento analógico se concibe como la transferencia de parte del conocimiento de un dominio ya conocido (dominio fuente) a un dominio nuevo (dominio meta u objeto); una analogía permite establecer un puente entre lo que ya se conoce y lo desconocido; la comprensión de un modelo analógico implica un sistema de conocimiento interconectado, y no la mera enumeración de relaciones; los modelos analógicos proporcionan cadenas relacionales dinámicas frente a las relaciones estáticas; los modelos se constituyen a partir de una combinación de elementos tanto de la realidad modelada como de los modelos científicos. Además implican simplificaciones y aproximaciones que han de ser decididas independientemente de requisitos teóricos o de condiciones de datos; los modelos analógicos permiten representar de formas mas sencillas los fenómenos complejos de la naturaleza, (Justi, 2006.).

En el caso de las imágenes, como formas de representación mental, como representaciones internas o maneras de re-presentar internamente el mundo externo, permitiendo explicar las características de un sistema y formular conclusiones. De esta forma, por ejemplo, para explicar equilibrio dinámico, velocidades iguales, reversibilidad, constante de equilibrio, alteraciones del equilibrio y catálisis lo hacen a través de las analogías de tipo familiar, juegos, experimentos, flujos o transferencia de fluidos y máquinas. Sin embargo muchas de estas analogías promueven otras concepciones altemativas o caer en otros errores, lo que aconsejan estos investigadores emplear mas de una analogía para representar un mismo fenómeno. En el caso de las analogías que recurren a los juegos existe una dificultad ya que se requieren de procesos de tipo matemático para su compresión lo que ocasiona, en algunos casos, el rechazo a este tipo de actividades. Se hace hincapié para que los estudiantes comprendan de forma mas significativa que los cientúficos también recurren al uso de analogías para divulgar sus ideas a otros científicos, para hacer mas accesible aspectos que son complejos y con mayor razón se justifica en los proceso didácticos.

Por otro lado, existe una tendencia en las investigaciones didácticas a afirmar que uno de los modelos que apoyaría la comprensión de los fenómenos que ocurren en el equilibrio químico es el de las colisiones ya que permite la construcción de un modelo en la medida en que facilita pensar en el nivel micro lo que sucede en el equilibrio químico (Raviolo, 2006) Una teoría que si bien puede ser avalada didácticamente, los análisis histórico epistemológicos señalados como "choquismo" no ha contribuido científicamente a esclarecer el problema de la cinética de las reacciones químicas (Bachelard, 1979)

En consecuencia se hace necesario que el docente que se enfrenta a la enseñanza de este contenido curricular en un programa de formación de profesores de química, construya sus estrategias acudiendo a preguntas como las siguientes: ¿Qué es lo fundamental en el equilibrio químico? ¿Cómo hacer del equilibrio químico un objeto de conocimiento en el aula? ¿Qué relaciones ha de establecer ese docente entre la estructura conceptual y metodológica del equilibrio químico, objeto de trabajo en el aula, y sus aspectos sociales, culturales, políticos, económicos, medioambientales y éticos del contexto en el que se hace objeto de enseñanza esta temática curricular? Estos interrogantes posibilita una enseñanza contextualizada se espera que aporte una mirada diferente de la habitual. En este sentido se aspira a que los profesores de química en formación inicial logren un aprendizaje crítico y reflexivo, inscrito en la historia de la construcción del modelo científico para el equilibrio químico.

\section{Una revisión histórica del modelo de equilibrio químico}

La construcción histórica de lo relacionado con lo que se denomina equilibrio químico parte con los aportes de J. Watts en 1824 y de S. Camot (1796 - 1832) que postularon una máquina que funcionaba en un cido ideal reversible. $Y$ los aportes de B. Thomson en el que conduyó que el 
calor no era una sustancia. Inidalmente, J. R. Mayer (1814 - 1878) y R. Causius ( 1822 - 1888) estructuran matemáticamente la primera y la segunda ley de la termodinámica introduciendo el concepto de entropía. Esto es, a finales del siglo XIX la termodinámica dásica estaba formulada conceptual, metodológicamente y matemáticamente (Schneer, 1975). W. Oswald (1853 - 1932), J. H. Van't Hoff. (1852 - 1911), asociados con S. Anthenius (1839 - 1927) se hacen la pregunta por la estabilidad de los compuestos químicos y el problema de la cinética de las reacciones, deciden leer el fenómeno químico desde la termodinámica formulada. Construyeron, entonces, lo que se conoce como la fisicoquímica para cuyas explicaciones introdujeron los conceptos de entalpía, entropía, función de trabajo de Gibbs y la de Helmholtz (Loquemann, 1960). Las reconstrucciones históricas que hablan de como la termodinámica dásica se convirtió en una manera de explicar los procesos químicos se constituyó en un problema de interpretación, y dado que la formación matemática de los químicos de la época no pasaban de ser operaciones algebraicas elementales, tuvieron que dedicarse a escribir libros didácticos para que su propuesta fuera admitida (Brock, 1998)

En este orden de ideas, G. Lockermann (1960), menciona el concepto de equilibrio químico para explicar en inicio de los procesos fisicoquímicos como objeto de conocimiento de una ciencia autónoma, sobre la necesidad de explicar las propiedades físicas de los elementos y sus compuestos y de hallar las leyes físicas presentes en los procesos químicos. Así, M Guldberg (1836-1902) y M. Waage (1833-1900), proponen condusiones mas precisas de las formuladas hasta la época, acerca de las relaciones entre la masa química y la acción química, proponiendo la ley de la acción de las masas químicas manifiestan que la acción química de una sustancia es proporcional a su masa.. Otros aportes de estos dos cient́ficos fueron plantear una teoría sobre velocidad de reacción y explicar los equilibrios químicos como sistemas dinámicos y no estáticos. J. H. Van't Hoff, propone el equilibrio en función de la concentración y de la temperatura, interpretado como dos procesos opuestos con diferentes velocidades de reacción (procesos reversibles) y dilucidó las fómmulas matemáticas para las reacciones mono y bimoleculares.

R. Justi y J. Gilbert (1999), realizaron indagaciones sobre momentos históricos que aportan a la comprensión del equilibrio químico. Recurren a modelos o teorías de la física, para facilitar la comprensión de los fenómenos micro en el equilibrio químico. El primero está centrado en fuerzas dentro de un sistema mecánico para explicar las afinidades como fuerzas de atracción y repulsión que dependen de la naturaleza de las sustancias; el segundo plantea que la velocidad de reacción es proporcional a las masas activas de las sustancias reaccionantes. En el equilibrio el número de moléculas que se están descomponiendo en un cierto tiempo es igual al número de moléculas que se están formando. $Y$, el tercero centrado en la energía asume que el calor desprendido en una reacción es una medida de la afinidad química, y el estado de equilibrio se logra cuando el sistema químico produce un máximo de trabajo y alcanza un potencial enérgico mínimo. Este sería un ejemplo que se haría objeto de trabajo en el aula, como una demostración de cómo los modelos propuestos por los cientúficos son discutidos, refutados y de difícil aceptabilidad, lo que llevaría a pensar una ciencia en constante construcción y no en modelos acabados o terminados.

\section{La comprensión del equilibrio quimico: un problema didáctico de estrategias}

La propuesta contribuiría a una formación en química a través del equilibrio químico. Que se asumińa como pretexto para construir/re-construir habilidades, el uso que se hace de dicho conocimiento en todos los aspectos de la sociedad, en lo político, lo económico, lo cultural, lo medioambiental y lo ético, describiendo y discutiendo de qué formas se aplica y se utiliza la ciencia para resolver problemas locales y globales, evaluar los beneficios y limitaciones de la ciencia y sus aplicaciones, valorar cómo la ciencia y la tecnología están integradas en la producción de conocimiento. Estas reflexiones y discusiones encausaría al docente de química en formación 
dispondrá de fundamentos para su ejercicio como profesional en la formación de ciudadanos para el desempeño eficaz y efectivo en una sociedad.

En las investigaciones realizadas sobre el desarrollo de equilibrio químico se menciona el Proceso Haber, pero no se reportan indagaciones al respecto. Este sería el componente motivador para iniciar el proceso de enseñanza-aprendizaje del Equilibrio químico por cuanto aporta invaluable información para ser analizada y discutida en el aula de dase en todos los aspectos anteriormente mencionados y con una construcción conceptual mas contextualizada en lo referente al problema en cuestión. Se propone entonces, hacer un estudio investigativo del proceso Haber y su relación con equilibrio químico, estudio que permite revisar los factores que afectan el equilibrio químico como lo son reversibilidad, velocidades iguales, constante de equilibrio y alteración del equilibrio. Permite, además, indagar sobre un momento histórico como lo fue la primera guerra mundial. Realizado este análisis, los docentes en formación refiexionarían sobre el papel de la ciencia en la sociedad.

En primer lugar, se seleccionaran las habilidades que se van a potenciar con dicha temática, entre ellas analizar, por cuanto permite examinar y descomponer la información en sus partes constituyentes, identificar pautas y relaciones, causas, errores e ideas principales. Otra habilidad es la construcción de modelos, que permiten describir y explicar un fenómeno a través de representaciones y por último la habilidad de experimentar, ya que permite diseñar y contrastar una serie de hipótesis a través de la capacidad de organizar, registrar y procesar información en la formulación de o condusiones que se sustenten en la explicación cient́fica y en la interpretación razonada de los datos.

A los Profesores en formación se les propone una misión, actividad motivante por cuanto involucra afectivamente a quienes la realizan ( Aristizabal, 2005). Una parte fundamental de la misión consistirá en cómo mejorar, la calidad del aire de una zona habitacional o industria de la ciudad planteado por un artículo de prensa, por ejemplo: "Localidades de Puente Aranda, Kennedy y Fontibón tienen el aire más contaminado de Bogotá" Lunes, 03 de diciembre de 2007: En I http://uww. bogotaampm.com/contenido/index.php?option=com content\&task=view\&id=19958Ite mid=99999999

Sobre esa lectura los docentes en formación han de elaborar soluciones, ya sean hipotéticas o soluciones reales y recurrir a los modelos en su explicación, se informen y trabajen el proceso Haber en términos de equilibrio químico. Para iniciar dicha misión se les propone indagar sobre los siguientes interrogantes: ¿Cómo se puede producir amoniaco? ¿Quién invento el proceso y en qué época? ¿Qué apoyos conceptuales y experimentales utilizó? ¿Por qué fue importante la producción de amoniaco y qué otras aplicaciones tiene? ¿Qué procesos diferentes a la producción de amoniaco, se puede realizar a través de mismo mecanismo o que variaciones se le pueden hacer? ¿Qué máquina se construyó para la producción de amoniaco y cómo funcionaba? ¿Cómo se controlaron variables como la temperatura y la presión en dicha máquina? ¿Cuál fue la eficiencia de dicha máquina en función del rendimiento y producción del amoniaco? ¿Qué dificultades tuvieron que superar en la producción del amoniaco y cómo se superaron? ¿Qué representaciones simbólicas se emplearon para describir este proceso y cuál su significado? ¿Qué implicaciones sociales, políticas, económicas, medioambientales, culturales y éticas, trajo consigo la producción de amoniaco y de otros productos, producidos por el mismo proceso? ¿Qué beneficios y desventajas trajo consigo la producción de amoniaco? ¿Teniendo en cuenta el proceso Haber, proponga un modelo con el que intente solucionar el problema de contaminación en la localidad referenciada.

Las actividades propuestas, son: lectura de representaciones analógicas para la comprensión del equilibrio dinámico, velocidades de reacción y constante de equilibrio; representaciones simbólicas de equilibrio químico (pensamiento abstracto de nivel micro); indagación históricoepistemológica y conceptual del proceso de Haber y elaboración de un documento por parte de los 
docentes en formación (analicen formas de aplicar y utilizar la ciencia para resolver problemas locales y globales, evaluar los beneficios y limitaciones de la ciencia y sus aplicaciones, así como sus efectos en la vida y en la sociedad); Presentación y discusión sobre los documentos presentados; con base en lo trabajado respecto al proceso Haber, en la perspectiva de equilibrio químico; en pequeños grupos, elaboraran una propuesta admisible de solución a la situación que vive la localidad de puente Aranda referido a la contaminación por ozono con apoyos de tipo experimental; la evaluación acerca de la comprensión del equilibrio químico se hará con base en las aproximaciones que los grupos hacen en cuanto a los modelos que sobre esta temática se acepta en la comunidad cient́fica. Se espera con esta propuesta de docencia solucionar problemas de comprensión sobre los fundamentos centrales que estructuran la química como ciencia, asumida esta como una construcción histórica y social para la propuesta de soluciones a problemas locales y globales relacionados con su objeto de conocimiento e investigación.

\section{Bibliografía}

Aristizabal, A. (2005). Los conceptos de calor y temperatura desde la enseñanza de las competencias cognoscitivas y los estándares de competencia. Tesis de maestría. Bogotá, D. C. Universidad Pedagógica Nacional

Bachelard, G. (1979). El racionalismo aplicado. Buenos Aires: Paidos

Brock, W. H. (1998). Historia de la química. Madrid: Alianza.

Just, R. y Gilbert, J. (1999). History and philosophy of science through models: the case of chemical kenetics. Science education, 61(6), 287-307.

Raviolo, A. (2006). Las imágenes en el aprendizaje y la enseñanza del equilibrio químico. Educación Química.17 (No extra), 300-307. 